\title{
The Effects of Shot Changes on Eye Movements in Subtitling
}

\author{
Izabela Krejtz \\ University of Social Sciences \\ and Humanities
}

\author{
Agnieszka Szarkowska \\ University of Warsaw
}

\author{
Krzysztof Krejtz \\ University of Social Sciences \\ and Humanities \\ Information Processing Institute
}

\begin{abstract}
In this paper we address the question whether shot changes trigger the re-reading of subtitles. Although it has been accepted in the professional literature on subtitling that subtitles should not be displayed over shot changes as they induce subtitle re-reading, support for this claim in eye movement studies is difficult to find. In this study we examined eye movement patterns of 71 participants watching news and documentary clips. We analysed subject hit count, number of fixations, first fixation duration, fixation time percent and transition matrix before, during and after shot changes in subtitles displayed over a shot change. Results of our study show that most viewers do not re-read subtitles crossing shot changes.
\end{abstract}

\section{Keywords: subtitling, shot changes, deaf and hard of hearing viewers, eye movements, transition matrix}

\section{Introduction}

\section{Subtitling and shot changes}

It has been widely accepted in the professional literature on subtitling that subtitles should not be displayed over shot changes (see ITC Guidance on Standards for Subtitling, 1999; Díaz Cintas \& Remael, 2007; Aleksandrowicz-Grzyb, 2013). The reasons for this rule, as explained by Robson (2004: 184), is a conviction that "research has shown that if a caption remains on the screen when the scene changes behind it, viewers will automatically start reading the caption over again, assuming that the caption changed with the scene". At the same time, fast film editing often makes it impossible not to cross any film cuts within a subtitle, which is confirmed by Wildblood (2002: 41), as cited in Sokoli (2011: 121), "Not going over cuts is the first thing a novice subtitler learns. How often we have to break this rule varies from production to production. Rarely do we get a film where we can fit more than 90 per cent of the subtitles between cuts. I believe I always manage to squeeze 60 per cent of them into a single shot". Given the above, it is admissible for subtitles to be displayed over shot changes whenever it is absolutely necessary, but at the same time it is recommended that if a subtitle does go over a shot change, it should remain on the screen for at least several frames before and after the cut (ITC Standards on Guidance for Subtitling, 1999: 12).

In spite of the widespread popularity of the claim that subtitles displayed over shot changes induce re-reading of subtitles, the scientific evidence to support this claim is hard to find. We do not know of more than two eyetracking studies which examined the influence of shot changes on eye movements of people reading subtitles ${ }^{1}$. One of them is a study by de Linde and Kay (1999), which investigated the process of reading subtitles in two clips: one with a small number of cuts per subtitle (1.3 shot change per subtitle) and the other with a large number of cuts per subtitle ( 3.5 shot changes per subtitle). Their results show that when watching the clip with more cuts per subtitle, participants had a higher number of deflections, i.e. gaze shifts between the image and the text (1999: 61) than in the case of the other clip. The

1 The Authors were unable to access the second study by Baker (1982). 
higher number of deflections, however, may also have stemmed from the content of the clip, featuring how an advertisement was made, which may have made the participants look more at the image simply to see what was being shown. Another potential methodological problem with this clip was that - although it was authentic material from the $\mathrm{BBC}$ - the number of shot changes per subtitle was much higher than the professional subtitling standards (3.5 shot changes per subtitle on average, with one subtitle displayed over as many as nine shot changes). Last but not least, the higher number of deflections obtained in this study does not mean that the participants actually re-read the subtitles, but it only suggests that they were shifting their gaze from the subtitle area to the centre of the image more often than in the case of subtitles which did not cross shot changes. Interestingly, de Linde and Kay (1999) themselves also report that "eye movement research (Baker, 1982) has suggested that shot changes which occur while a subtitle is being shown cause viewers to return to the beginning of a partially read subtitle and start re-reading", but they do not provide any evidence for this claim in their own study.

\section{Edit blindness}

Human cognition enables us to interpret events as continuous even though in reality they are not. A good example of this phenomenon is the fact that viewers experience changing scenes in films as presenting a coherent narrative and do not pay attention to numerous cuts throughout the film. Although a 90-minute Hollywood production can on average contain from one to two thousand edits and a change of viewpoint appears every 2.7 to 5.4 seconds (see Bordwell \& Thompson, 2001; Smith \& Henderson, 2008: 2), viewers tend to be unaware of standard film editing techniques and their film watching experience usually goes undisturbed by cuts. This phenomenon has come to be known as 'edit blindness' (Smith \& Henderson, 2008: 2).

Edit blindness, whereby film viewers suspend their disbelief and are unaware of some film edits, is possible when filmmakers abide by the rules of continuity editing, i.e. a system of rules regarding film cuts aimed at making the narrative logical and coherent for viewers, ensuring smooth transitions in time and space between cuts both within and across scenes. According to Smith and Henderson (2008: 2), "film editors assume that one of the main benefits of adhering to the Continuity Editing Rules is edit blindness".

Previous studies have confirmed that when continuity editing rules are violated, viewers tend to become aware of discontinuous cuts more quickly than when the rules are adhered to (see d'Ydewalle \& Vanderbeeken, 1990; Smith \& Henderson, 2008). In their study examining whether shot transitions are perceptually disruptive, d'Ydewalle et al. (1998) analysed eye movement patterns in three types of editing errors: first-order editing errors, second-order editing errors and third-order editing errors. They found that "eye movements were apparently uninfluenced by the first-order editing errors, the jump cuts" (1998: 366) and observed that first-order cuts did not make the participants redirect their gaze to other positions on the screen. Similarly, Smith and Henderson (2008) found that straight cuts within scenes were missed by participants significantly more often than betweenscene cuts, prompting the authors to state that in contrast to between-scene cuts, scene continuity maintained by within-scene cuts increases edit blindness (1998: 8).

In this article we examine subtitles displayed over within-scene cuts and the potential influence of such cuts on the process of subtitle reading and film watching. We hypothesise that it is possible that just as viewers tend to be blind to certain film edits, they may also be blind to within-scene cuts with subtitles in the sense that their gaze is not affected by a change of shot.

\section{Influence of hearing loss on subtitle reading patterns}

As stated by Kelly (2003: 230), "the prevalence of low comprehension among deaf readers has been documented for decades". Dyer et al. (2003: 215) go as far as to say that "in most deaf people, reading and writing skills fail to achieve levels appropriate to the age and intelligence of the student, typically lagging their peers by several years in the final years of obligatory schooling". Indeed, a number of previous studies on reading showed systematic differences between deaf, hearing and hard of hearing people when it comes to reading patterns (Conrad, 1977; Torres \& Santana Hernández, 2005; Trybus \& Karchmer, 1977) as well as watching subtitled films (de Linde \& Kay, 1999: 12, Szarkowska et al., 2011, Ward et al., 2007). Hertzog et al. (1989) found that "deaf students benefited from captioning presented at the eighth-grade level" 
(Easterbrooks \& Stephenson, 2006: 387). Some studies stress the importance of subtitling in language learning, particularly vocabulary acquisition and improving reading skills (Koskinen et al., 1986), though some others also found that subtitling reading speeds are sometimes too fast for many deaf viewers to follow (Jensema, 1998; Shroyer \& Birch, 1980).

The results obtained in reading studies were corroborated by the results of eyetracking studies on subtitling, which also showed differences in subtitle reading patterns between people with and without hearing impairments. For instance, Szarkowska et al. (2011) found that deaf viewers spent more time on reading subtitles than the hearing, which was demonstrated by a higher proportion of dwell time spent on subtitles and a higher number of fixations in the subtitle. The proportion of time spent in the subtitle area is a function of the subtitle reading speed and amount of text in the subtitle (see Romero Fresco, 2011). In a study by Jensema et al. (2000) it was found that the increase of the subtitle reading speed from 100 words per minute (wpm) to 180 wpm resulted in an increase in the mean percentage of time spent looking at subtitles from $82 \%$ to $86 \%$.

In view of the above, in the present study we aimed to test a possible influence of shot changes on the reading process of subtitles among hearing, hard of hearing and deaf subjects. We predicted to find differences between these three groups in subtitle viewing patterns and we hypothesised that deaf participants would spend more time in the subtitle area than hearing viewers, both before and after the shot change. What we also wanted to find was whether the presence of shot changes in any way affected the subtitle reading patterns of any of the groups.

In what follows we report on a part of a larger eyetracking study on subtitling reading patterns conducted among hearing, hard of hearing and deaf subjects.

\section{Method}

\section{Participants}

The total number of participants analysed in this study was 71 , out of whom 21 were deaf $\left(M_{\text {age }}=24.30, S D=\right.$ 14.30 , out of whom 13 were male), 19 hard of hearing $\left(M_{\mathrm{age}}=32, S D=18.80,11\right.$ male $)$, and 31 hearing $\left(M_{\mathrm{age}}=\right.$
28.65, $S D=14.70,9$ male). The differences in age were not significant, $F(2,68)=1.50, p>0.05$.

\section{Material}

In this study, we analyse 20 subtitles displayed over shot changes from two film genres: 9 subtitles from documentaries (five subtitles from Super Size Me, 2004, dir. Morgan Spurlock; two from Roman Polański: Wanted and Desired, 2008, dir. Marina Zenovich and two from Polskie Państwo Podziemne, 2002, dir. Andrzej Sapija) and 11 subtitles from news programmes (three subtitles from Teleexpress and eight from Fakty). Table 1 presents basic characteristics of the subtitles in the two types of programmes. All clips were subtitled in Polish with the reading speed of 12 characters per second (cps) using EZTitles subtitling software. The frame rate for all the videos was $25 \mathrm{fps}$.

\section{Table 1}

Characteristics of subtitles by the type of clip (averaged per subtitle).

\begin{tabular}{lcc}
\hline & Documentaries & News \\
\cline { 2 - 3 } Number of words & 6.44 & 6.77 \\
Characters with spaces & 42.77 & 46.11 \\
Duration (seconds:frames) & $3: 14$ & $3: 20$ \\
Duration before a shot change* & 55 & 49 \\
Duration after a shot change* & 35 & 45 \\
\hline
\end{tabular}

Note. * frames

A shot is here understood, following d'Ydewalle et al. (1998), as "a single run of the camera" and a shot change, also referred to as a cut, is taken to mean a "transition between the end of one shot and the beginning of the next one". All the cuts in this study were straight cuts, i.e. "instantaneous transitions between shots, not gradual effects such as dissolves or fades" (Smith \& Henderson, 2008: 7).

In accordance with professional subtitling standards, all subtitles displayed over shot changes remained on the screen at least 20 frames before a shot change and 20 frames after the shot change. All subtitles displayed over shot changes in our study belonged to the same scene; that is to say, while some subtitles crossed film cuts within a scene, none of them crossed film cuts between 
scenes, in accordance with within-scene editing rules (Bordwell \& Thomspon, 2008).

\section{Procedure}

After signing a written consent form, participants were seated in front of a monitor with an eye-tracker, where 9-point calibration and validation were performed. The test began with a few questions eliciting personal information. All the participants watched the videos with sound presented through speakers (see Fig. 1). They were instructed to watch the clips carefully, as they would have to answer some questions related to the clip content. After viewing each clip, participants had to answer three closed-ended comprehension questions related to the content of the clip.

\section{Eye movement data acquisition and analyses}

Participants' eye movements were recorded with SMI RED eyetracking system with a sampling rate of $120 \mathrm{~Hz}$. Participants sat in front of a 21-inch monitor at a distance of about $60 \mathrm{~cm}$. SMI BeGaze software was used for fixation and saccade detection and raw data cleaning. For statistical analysis and data preparation we used IBM SPSS Statistics and R (R Development Core Team, 2011). Effects of mixed design analyses of variance are reported with Greenhouse-Geisser correction if the sphericity assumption was violated, and the post hoc comparisons of simple effects were calculated with Bonferroni correction for multiple comparisons. Extreme scores were substituted with mean values whenever necessary.

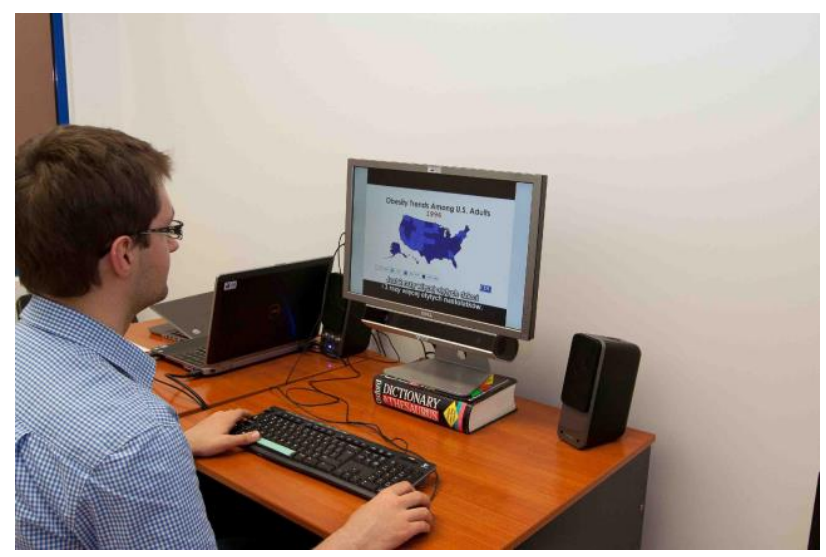

Figure 1. Experimental set-up with a participant in front of the monitor, loudspeakers and eyetracker.
The influence of shot changes on subtitle re-reading was tested using the following eyetracking measures:

- subject hit count, i.e. the number of subjects who looked at the beginning of subtitle Area of Interest (AOI) before and after a shot change.

- number of fixations on AOI marked as subtitle beginning before and after the shot change. A larger number of fixations on the AOI before a shot change than after the shot change may indicate that viewers did not re-read the subtitles. A similar number of fixations before and after the shot change, in contrast, would point to the re-reading process.

- fixation time percent on AOI marked as subtitle beginning before and after the shot change. It is the sum of the fixation durations inside the AOI divided by clip/subtitle duration (SMI Manual, 2011) This measure was added to control for the unequal length of subtitles presentation before and after the shot change (see Table 1).

- first fixation duration (FFD) on the AOI marked as the subtitle beginning.

- transition matrix, i.e. the number of fixation transitions inside and between AOIs: (1) the beginning of the subtitle, (2) the rest of the subtitle and (3) the image (see Fig. 2). Each transition matrix cell (see Fig. 5 and Fig. 6) represents the number of transitions from the AOI presented in the row to the corresponding column AOI. The value of each cell was normalized by the marginal sum of each cells row. Each cell value shows the probability that a fixation coming from the row AOIs will be placed in one of the column AOIs. The diagonal cells of transition matrix represent subsequent fixations on the same AOI (i.e. withinAOI transitions). Although some authors (Holmqvist et al., 2011) argue that "a saccade within an AOI is not and should not be called a transition", but rather a within-AOI saccade and as such reported as a structural zero in the transition matrix, in this study we decided to retain the term 'within-AOI transitions' in line with the manufacturer's manual. The reason for this is that we were interested both in eye movements between AOIs and within an AOI, and thus we did not wish to treat within-AOI transitions as structural zeroes. 


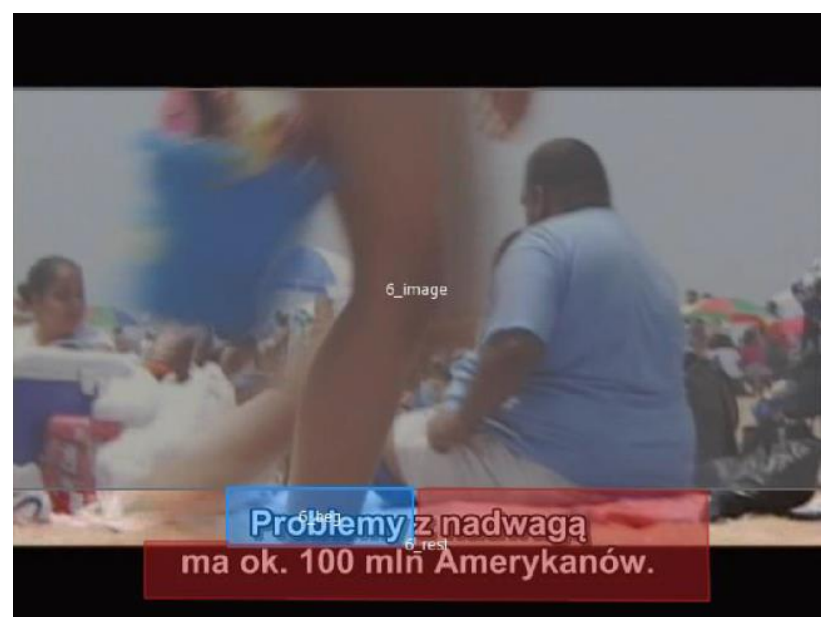

Figure 2: Sample of stimulus with AOIs on beginning (in blue), the rest of the subtitle (in red) and image (in pale grey).

\section{Results}

\section{Subject hit count}

We first examined any potential differences in the subject hit count, i.e. the percentage of people who looked at the beginning of subtitle before and after a shot change occurred. Our prediction was that shot changes do not evoke too much re-reading, so the number of viewers who looked at the subtitle beginning after the shot change should be smaller than before shot change. We verified this prediction with a mixed $2 \times 2$ analysis of variance with clip type (documentary vs. news) as between-subtitle factor and subtitle presentation (before vs. after shot change) as within-subtitle factor and the percentage of subject hit counts the AOIs on subtitle beginning as a dependent variable. In this analysis we treated subtitles with shot changes as cases. In line with prediction, $65 \%$ participants looked at the beginning of subtitle before a shot change occurred, compared to only $33 \%$ who looked there after the shot change. This difference was statistically significant, $F(1,18)=87.27, p<0,001$, eta $^{2}=$ 0.829 . The difference between documentaries and news was also significant, $F(1,18)=17.00, p<0.001$, eta $^{2}=$ 0.486 . Documentary subtitles received higher percentage of hits $(M=57.22, S E=2.80)$ than news $(M=41.60, S E$ $=2.54$ ). This result cannot be attributed to subtitle length or duration, as subtitles in news programmes were slightly longer both in terms of word and character count and of subtitle duration. It therefore appears that the difference in the percentage of hits may be due to language understanding of participants: two of the
Krejtz, I., Szarkowska, A. \& Krejtz, K. (2013) The Effects of Shot Changes on Eye Movements in Subtitling

documentaries had the English soundtrack and were subtitled into Polish, whereas the news clips were in Polish with Polish subtitles.

\section{Number of fixations}

We compared the number of fixations on the beginning of subtitles before and after a shot change. If viewers indeed re-read subtitles on shot changes, this would be reflected in a similar number of fixations before and after the cut change. In contrast, a smaller number of fixations on the subtitle beginning after a shot change would indicate that viewers do not re-read subtitles. To test this hypothesis, a mixed-design analysis of variance was conducted with group (deaf vs. hard of hearing vs. hearing) and type of clip as between-subjects factors and subtitle presentation (before vs. after shot change) as the between-subjects factor. The dependent variable was the number of fixations on the beginning of subtitle. We observed a main effect of subtitle presentation, $F(1,68)=213.91, p<0.001 ;$ eta $^{2}=0.759$. The number of fixations on subtitle beginning was significantly higher before the shot change $(M=1.48, S E=0.82)$ than after the shot change $(M=0.55 ; S E=0.04)$. In general, deaf and hard of hearing participants made significantly more fixations $\left(M_{\text {deaf }}=1.21, S E=0.10, M_{H o H}=1.14, S E=0.11\right)$ to the beginning of subtitle than hearing participants $(M=0.70, S E$ $=0.08), F(2,68)=9.67, p<0.001$, eta ${ }^{2}=0.221$. Interestingly, an interaction between group and subtitle presentation was observed, $F(2,68)=3.86, p<0.05$, eta $^{2}=$ 0.102 (see Fig. 3). In all groups there was a significant drop in the number of fixations to the beginning of subtitle after a shot change; the difference between hearing impaired and hearing participants remained significant. No differences were observed in terms of the type of clip.

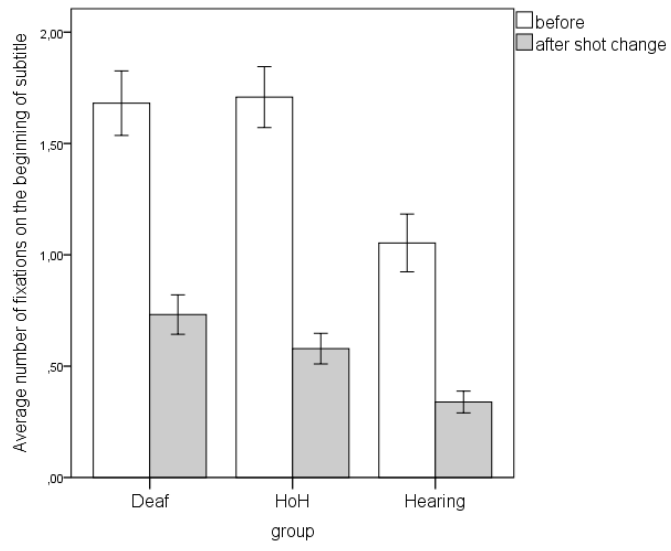

Figure 3. Average number of fixations fixation on the beginning of subtitle before and after a shot change by group. The whiskers represent +/- ISE. 
To control for the differences in the duration of subtitle presentation before and after shot change, we analysed the percent of fixation time on the beginning of subtitles before and after the shot change. A mixeddesign analysis of variance was conducted with group (deaf vs. hard of hearing vs. hearing) and type of clip as between-subjects factors and subtitle presentation (before vs. after shot change) as the between-subjects factor. This analysis supported the pattern of results obtained for fixation count, and was largely consistent with our expectations. We observed a main effect of subtitle presentation (before vs. after shot change), $F(1,68)=$ $181.05, p<0.001 ;$ eta $^{2}=0.727$. The percentage of fixation time on subtitle beginning was significantly higher before the shot change $(M=0.44, S E=0.03)$ than after the shot change $(M=0.18 ; S E=0.01)$. On average, deaf and hard of hearing participants spent more time on the beginning of subtitles $\left(M_{\text {deaf }}=0.40, S E=0.33, M_{H o H}=\right.$ $0.35, S E=0.04)$ than hearing participants $(M=0.20, S E$ $=0.03), F(2,68)=11.60, p<0.001$, eta $^{2}=0.254$. Again, the interaction between group and subtitle presentation was observed, $F(2,68)=6.08, p<0.01$, eta $^{2}=0.152$ (see Fig. 4). In all groups there was a significant drop in the time spent on reading the beginning of subtitle after a shot change; the difference between hearing impaired and hearing participants remains significant after the shot change. Additionally, there was an interaction between the type of clip and shot change, $F(1,68)=44.30, p<$ 0.001, $e t a^{2}=0.394$. Beginnings of subtitles in documentary clips before the shot change attracted significantly more attention $(M=0.56, S E=0.03)$ than beginnings of subtitles in news clips $(M=0.33, S E=$ $0.03)$. This difference disappeared after shot change $\left(M_{d o c}\right.$ $\left.=0.20, S E=0.03 ; M_{\text {news }}=0.17, S E=0.02\right)$. The findings strengthen our claim that shot changes do not induce rereading.

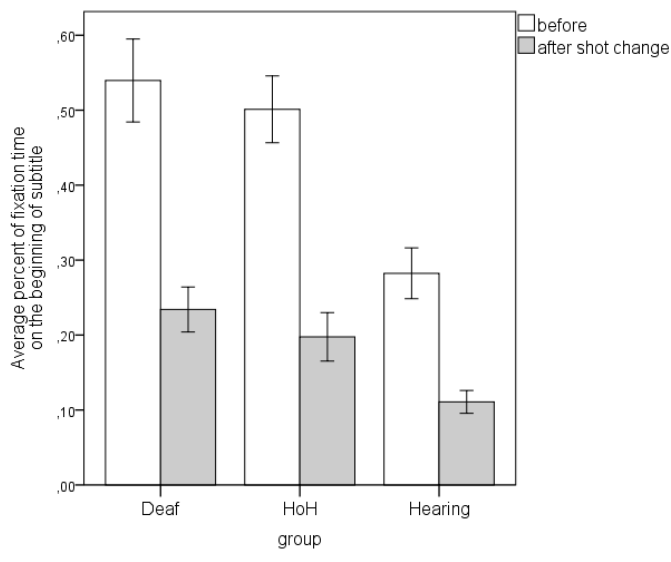

Figure 4. Average fixation time percent on the beginning of subtitle before and after a shot change by group. Note: the whiskers represent +/- 1SE.

\section{First fixation duration}

The next eyetracking measure we analysed was first fixation duration (FFD) on the AOI marked as subtitle beginning. Longer FFD is usually taken to reflect a larger processing effort on the part of the participants. Again, three way analysis of variance was carried out for first fixation duration with viewers (hearing, hard of hearing, deaf) as a between-subjects factor and two withinsubjects factors: subtitle presentation (before vs. after shot change) and type of clip (documentary vs. news).

We observed three significant main effects, but no interactions. Firstly, there was a main effect of subtitle presentation, $F(1,55)=16.07, \mathrm{p}<0.001$, eta ${ }^{2}=0.226$. The first fixation duration was significantly longer after shot change $(M=220.16, S E=3.65)$ than before the change $(M=195.67, S E=7.11)$, which may suggest that participants were trying to recall whether they had seen the subtitle before. Secondly, FFD after the cut change was longer in news programmes $(M=217.51, S E=5.94)$ compared to documentaries $(M=198.33, S E=5.72)$, $F(1,55)=8.02 ; p<0.01$, eta $^{2}=0.127$. Finally, the groups differed significantly, $F(2,55)=4.01, p<0.05$, eta $^{2}=$ 0.127 as deaf participants had longer first fixation duration $(M=222.53, S E=8.51)$ than hearing participants $(M=190.35, S E=7.86)$. 


\section{Transition matrix analysis}

By examining the transitions between three types of dynamic AOIs: (1) image, (2) subtitle beginning, and (3) the rest of the subtitle, we hoped to see which areas viewers most frequently moved their eyes to and from. We hypothesised that if subtitle re-reading indeed occurs on shot changes, then we will be able to observe transitions from the rest of the subtitle to the subtitle beginning during a shot change and after it. If, on the contrary, viewers continue to read the subtitle undisturbed by the shot change, this should be reflected in a relatively larger proportion of transitions from the subtitle beginning to the rest of the subtitle as well as within the rest of the subtitle AOI. Additionally, the transition matrix analysis makes it possible to see whether shot changes could have had any influence on subtitle reading patterns in terms of an increased number of shifts between the image and the subtitle.

We start with a comparison of transition matrices before, during and after the shot change (see Fig. 5). Transition matrix before a shot change was calculated from fixations starting from the appearance of subtitle on the screen to the last but one fixation before a shot change. Transition matrix for the shot change consists of the last fixations before the shot change and the first fixations after the shot change. Transition matrix after the shot change summarizes fixations from the second fixation after the shot change to the last fixation before the subtitle disappeared. The values in transition matrices were compared using a series of onesample proportions tests (e.g., Agresti, 2013).

The shot change produces a higher probability that the eyes will move from the subtitle to the image. The probability is significantly higher at the moment of shot change $\left(P=0.22, \chi^{2}(1)=96.15, p<0.001\right)$ and after the shot change $\left(P=0.19, \chi^{2}(1)=54.93, p<0.001\right)$, than before the shot change $(P=0.11)$. The difference between the proportion of transitions from the subtitle beginning to the image at the moment of shot change and after the shot change is not significant, $\chi^{2}(1)=2.93, p=0.09$. Analogous pattern was found for the probabilities of gaze shifts from the rest of the subtitle to the image. These results clearly suggest that when noticing a shot change, some viewers moved their eyes up from reading subtitles to the image in order to see what has changed on the screen.
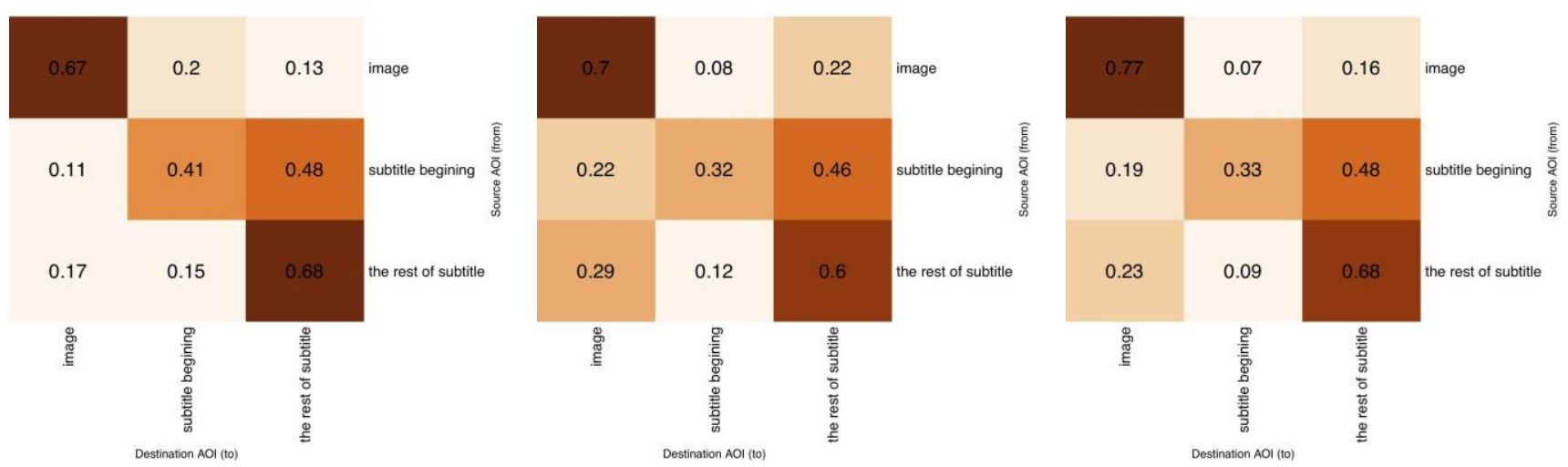

Figure 5. The fixations transition matrices before (left), during (middle) and after (right) the shot change.

In line with our expectations, the probability of gaze shifts from the image to the subtitle beginning is significantly lower during the shot change $P=0.08, \chi^{2}(1)$ $=394.48, p<0.001$, and after the shot change $P=0.07$, $\chi^{2}(1)=524.31, p<0.001$, than before $(P=0.20)$. The chance for re-fixating the beginning of the subtitle before the shot change is higher $(P=0.41)$ than after the shot change $(P=0.33), \chi^{2}(1)=40.93, p<0.001$. It is also significantly higher than refixations at the moment of shot change $(P=0.32), \chi^{2}(1)=52.91, p<0.001$. More importantly, there is a very low probability that participants who read the rest of the subtitle after the shot change will go back with their eyes to the beginning of the subtitle $(P=0.09)$ compared to the probabilities of transitions before the shot change $(P=0.15), \chi^{2}(1)=$ $141.48, p<0.001$. The probability of transition from the rest of subtitle to its beginning after the shot change is also significantly lower than during the shot change $(P=$ $0.12), \chi^{2}(1)=14.73, p<0.001$.

After the shot change, the probability that participants will continue to read the subtitle (i.e. that the next fixation from the subtitle beginning will land on the rest 
of the subtitle) remains the same as before the shot change $(P=0.48)$, and it is very similar to the probability at the moment of shot change $(P=0.46)$. The difference between the proportions of these transitions before the shot change and at the moment of shot change is not significant, $\chi^{2}(1)=1.73$, n.s., so is the difference of proportions between transitions at the moment of shot change compared to transitions after shot change, $\chi^{2}(1)<$ 1. These findings suggest that the reading process is relatively undisturbed during the shot change.
Taken together, these observations support our claim that shot changes do not induce subtitle re-reading. For some participants, some shot changes resulted in gaze shifts from the subtitle area to the image. We may speculate that the process of reading subtitles may be interrupted by shot changes, but it does not result in subtitle re-reading, as demonstrated by the low probabilities of going back to reading the subtitle beginning and high probabilities of fixating the rest of the subtitle.
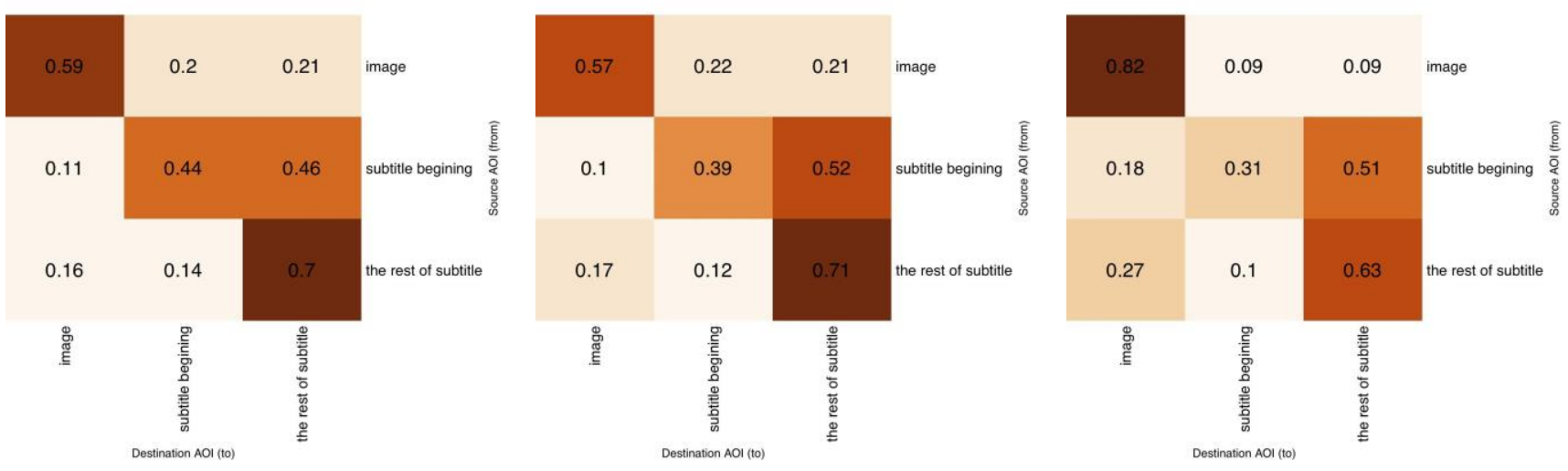

Figure 6. The comparison of transition matrices between deaf (left), hard of hearing (middle) and hearing (right) participants.

A comparison of transition matrices between the three groups of participants (see Fig. 6) shows that there is a slightly higher probability of re-fixating on the beginning of subtitle in the deaf group $(P=0.44)$ than in the hard of hearing $(P=0.39), \chi^{2}(1)=6.72, p<0.01$ or the hearing group $(P=0.31), \chi^{2}(1)=57.21, p<0.001$. The two last groups move their eyes more often to the rest of the subtitle after fixating its beginning $(P=0.51, P=$ 0.52 , respectively) than the deaf group $(P=0.46)$. The differences in proportions are significant for deaf vs. hearing groups, $\chi^{2}(1)=8.33, p<0.01$, and for hard of hearing vs. deaf group, $\chi^{2}(1)=11.88, p<0.001$.

Finally, we investigated transition matrices for each group of participants separately before, during and after the shot change (see Tab. 2). Hearing participants had significantly more image-to-image transitions than deaf participants before the shot change, $\chi^{2}(1)=444.10, p<$ 0.001 , after the shot change, $\chi^{2}(1)=339.80, p<0.001$, and at the moment of shot change, $\chi^{2}(1)=353.10, p<$ 0.001 , which indicates that hearing participants continued to look at the image, undisturbed by shot changes. Hearing participants also had significantly more imageto-image transitions than hearing-impaired participants before shot change, $\chi^{2}(1)=704.40, p<0.001$, after shot change, $\chi^{2}(1)=339.80, p<0.001$, and during the shot change, $\chi^{2}(1)=258.20, p<0.001$. These results clearly indicate that hearing viewers spent less time reading subtitles and thus had more time to look at the image. This is confirmed by other measures, whereby hearing subjects had fewer fixations on subtitles than the deaf and the hard of hearing.

For hearing participants, the number of transitions from the subtitle beginning to the image is significantly higher after the shot change than before, $\chi 2(1)=35.36, p$ $<0.001$. The difference is also significant when considering transitions from the rest of subtitle to the image, $\chi 2(1)=37.79, p<0.001$. For deaf participants, the probability of transitions from the subtitle beginning to the image is also significantly higher after the shot change than before, $\chi 2(1)=4.24, \mathrm{p}<0.05$, and from the 
rest of subtitle to the image, $\chi 2(1)=4.69, p<0.05$, however these differences are much smaller when compared to hearing participants (see Tab. 2). While the data provide no evidence to support the hypothesis that subtitles were re-read (by going back to subtitle beginning), our data show that shot changes affect the process of watching subtitled clips by slightly increasing the probability of gaze shifts from subtitles to the image.

Table 2. The probability of transitions between AOIs before, during and after shot changes by participant groups

\begin{tabular}{|c|c|c|c|c|c|c|c|c|c|}
\hline \multicolumn{10}{|c|}{ Before shot change } \\
\hline & \multicolumn{3}{|c|}{ To image } & \multicolumn{3}{|c|}{ To subtitle beginning } & \multicolumn{3}{|c|}{ To rest of the subtitle } \\
\hline & $\mathrm{D}$ & $\mathrm{HoH}$ & $\mathrm{H}$ & $\mathrm{D}$ & $\mathrm{HoH}$ & $\mathrm{H}$ & $\mathrm{D}$ & $\mathrm{HoH}$ & $\mathrm{H}$ \\
\hline From image & 0.49 & 0.42 & 0.78 & 0.30 & 0.37 & 0.13 & 0.21 & 0.21 & 0.09 \\
\hline From subtitle beginning & 0.11 & 0.09 & 0.15 & 0.46 & 0.41 & 0.35 & 0.43 & 0.50 & 0.50 \\
\hline From rest of the subtitle & 0.14 & 0.14 & 0.23 & 0.17 & 0.16 & 0.14 & 0.69 & 0.70 & 0.64 \\
\hline \multicolumn{10}{|c|}{ At the moment of shot change } \\
\hline & $\mathrm{D}$ & $\mathrm{HoH}$ & $\mathrm{H}$ & $\mathrm{D}$ & $\mathrm{HoH}$ & $\mathrm{H}$ & $\mathrm{D}$ & $\mathrm{HoH}$ & $\mathrm{H}$ \\
\hline From image & 0.47 & 0.52 & 0.82 & 0.14 & 0.11 & 0.05 & 0.39 & 0.36 & 0.13 \\
\hline From subtitle beginning & 0.19 & 0.11 & 0.36 & 0.35 & 0.38 & 0.22 & 0.46 & 0.51 & 0.41 \\
\hline From rest of the subtitle & 0.23 & 0.26 & 0.39 & 0.13 & 0.10 & 0.12 & 0.64 & 0.64 & 0.49 \\
\hline \multicolumn{10}{|c|}{ After shot change } \\
\hline & $\mathrm{D}$ & $\mathrm{HoH}$ & $\mathrm{H}$ & $\mathrm{D}$ & $\mathrm{HoH}$ & $\mathrm{H}$ & $\mathrm{D}$ & $\mathrm{HoH}$ & $\mathrm{H}$ \\
\hline From image & 0.64 & 0.64 & 0.85 & 0.11 & 0.11 & 0.05 & 0.24 & 0.25 & 0.10 \\
\hline From subtitle beginning & 0.14 & 0.18 & 0.27 & 0.40 & 0.33 & 0.24 & 0.46 & 0.49 & 0.49 \\
\hline From rest of the subtitle & 0.17 & 0.21 & 0.32 & 0.10 & 0.09 & 0.08 & 0.73 & 0.70 & 0.59 \\
\hline
\end{tabular}

Note. $\mathrm{D}$ - deaf, $\mathrm{HoH}$ - hard of hearing, $\mathrm{H}$ - hearing.

\section{Discussion}

\section{No evidence for re-reading subtitles on shot changes}

The present study verified whether shot changes induce the re-reading of subtitles in two film genres: documentaries and news programmes among three groups of participants: hearing, hard of hearing and deaf. While the results of this study provide no conclusive evidence to support the claim that subtitles are re-read when shot changes occur, shot changes do seem to have a small influence on watching subtitled material by triggering more gaze shifts (transitions) from the subtitle to the image. This is evidenced by a slightly increased probability of transitions from the subtitle beginning to the image and from the rest of the subtitle to the image in all groups of participants in the transition matrix analysis at the moment of shot change and after the shot change. A possible interpretation of this finding is that shot changes may have slightly disturbed the reading process of our participants, who as a result of the shot change shifted their gaze up to the image when reading a subtitle in order to check for any changes on screen and to look for the cause of the disturbance. A similar result was obtained by de Linde and Kay (1999), who found an increased occurrence of deflections from the subtitle to the image in the clip with a high number of shot changes. This result is also in line with our previous preliminary study on shot changes in feature films and documentaries subtitled at 15 cps (Szarkowska et al. 2014), where we found a similar pattern related to subtitles displayed over shot changes compared to those which did not cross any film cuts: participants had significantly more gaze shifts between subtitles and image in the case of subtitles displayed over shot changes compared to those which did not cross any cuts.

\section{Subtitle reading patterns before and after shot changes}

When comparing eye movement measures in this study, we observed a systematic drop in attention to the beginning of subtitles: significantly fewer participants looked at the beginning of subtitles after a shot change 
occurred, as evidenced by the subject hit count, the number of fixations, fixation time percent and the transition matrix analysis. Only about one third of all subjects looked at the subtitle beginning after the shot change and out of those who did only one in ten was likely to re-read the subtitle after the shot change by moving their eyes from the rest of the subtitle to the subtitle beginning. The probability of going back with their eyes to the beginning of the subtitle is slightly higher before the shot change, which can be explained by the fact that when noticing a new subtitle, many viewers moved their eyes from the image to the middle of the subtitle (marked at the rest of the subtitle AOI) and then adjusted their gaze to the beginning of the subtitle and began to read it.

The higher number of fixations and the higher percentage of fixation time on subtitle beginning before the shot change compared to after the shot change also demonstrate that before the shot change, i.e. when viewers saw a subtitle for the first time, they read it, but when they saw it again after the shot change, there was no need to read the entire area again once they established it had already been read. This may indicate a continuous progression in reading the subtitles: from the beginning to the end, which is also confirmed by transition matrix analysis, showing a lot of transitions from the subtitle beginning to the rest of the subtitle and within the rest of the subtitle area.

Those people who did look at the subtitle beginning after a shot change (about one third of all participants) had a significantly longer first fixation on this AOI than before the shot change. This can be interpreted as an indication of their increased processing effort as they were trying to establish whether they had already seen this subtitle or whether it is a new one. It also suggests a more regular reading pattern when the subtitle first appeared on screen (i.e. before the shot change) than when it was displayed after the shot change. In the first case, participants most probably read the subtitle, while in the second if they looked at the subtitle at all, they possibly re-initiated reading, but quickly realised that the same text is still displayed on screen. This interpretation can also be supported by the smaller number of fixations on subtitle beginning after the shot change.

\section{Differences in subtitle reading patterns among deaf, hard of hearing and hearing participants}

The results of this study also corroborate previous findings on differences in reading among deaf, hard of hearing and hearing people (Conrad, 1977; Di Francesca, 1971; Rodda \& Grove, 1987; Torres Monreal \& Santana Hernández, 2005; Szarkowska et al., 2011; Trybus \& Karchmer, 1977). In the present study, viewers with hearing impairments were found to have a higher number of fixations on subtitles, longer first fixation duration, and higher overall fixation time percent, which suggests they spent more time reading the subtitles and had therefore less time to watch the image. That deaf people had a significantly longer first fixation duration than hearing people may be attributed to the fact that the hearing could complement the information they were receiving through the verbal visual channel (i.e. subtitles) with the verbal auditory channel (i.e. the dialogue they could hear), whereas the deaf could only rely on the visuals to guide them to the right interpretation and it thus took them more time to establish that they had already read a subtitle.

However, when it comes to the influence of shot changes on the subtitle reading patterns we found no differences among the three groups of participants, which suggests that viewers behaviour in this respect is similar regardless of the hearing loss.

\section{Edit blindness}

Although the results of our study did not provide evidence for the commonly held belief that subtitles displayed over film cuts cause viewers to go back to the beginning of a subtitle to re-read it, our hypothesis that viewers are blind to, i.e. not affected by, shot changes in subtitles was not confirmed. The transition matrix analyses demonstrated that shot changes may cause viewers to move their eyes from the subtitle area to the image. This result corroborates the findings of the study by de Linde and Kay (1999), where an increased occurrence of deflections was detected in subtitles crossing film cuts.

\section{Conclusions}

All in all, the results of our study do not support the widespread assumption that subtitles displayed over shot changes induce re-reading of subtitles. Despite general 
differences in the reading patterns among hearing, hard of hearing and deaf people, the reading behaviour in relation to shot changes was very similar: subtitles displayed after shot changes attracted less attention in the case of all participants. Future studies need to verify the influence of the foreign language proficiency on subtitle reading patterns. It would also be interesting to introduce experimental control for film editing rules violations.

\section{Acknowledgements}

This study was supported by research grant No. IP2011 053471 "Subtitling for the deaf and hard of hearing on digital television" from the Polish Ministry of Science and Higher Education for the years 2011-2013.

We would like to gratefully acknowledge the many contributors to this project, including Maria Łogińska and Łukasz Dutka for their invaluable help and effort in carrying out the study, Tadeusz Adamiec for allowing us to conduct the study in the Institute of the Deaf in Warsaw, Wojciech Figiel for his enormous help in organizing the venue for the eyetracking tests, and finally to all the d/Deaf, hard of hearing and hearing participants who gave their time for our studies.

\section{References}

Agresti, A. (2013). Categorical Data Analysis. Hoboken, NJ: Wiley.

Aleksandrowicz-Grzyb, G. (2013). Ttumaczenia filmowe w praktyce ['Film translation in practice']. Fortima: Warszawa.

Baker, R.G. (1982) Monitoring Eye-movements While Watching Subtitled Television Programmes. A Feasibility Study, London: Independent Broadcasting Authority.

Bordwell, D., \& Thompson, K. (2008). Film art - an introduction (8th ed.). McGraw Hill.

Conrad, R. (1977). The reading ability of deaf schoolleavers. British Journal of Education Psychology, 47, $138-148$

de Linde, Z., \& Kay, N. (1999). The semiotics of Subtitling. Manchester: St. Jerome.
Díaz Cintas, J., \& Remael, A. (2007). Audiovisual Translation: Subtitling. Manchester: St. Jerome.

Di Francesca, S. (1971). Academic achievement test results of a national testing programme for hearingimpaired students. (Tech. Rep.). Washington, DC: Gallaudet College, Office of Demographic Studies.

d'Ydewalle, G., Desmet, G., \& Van Rensbergen, J. (1998). Film Perception: The Processing of Film Cuts. In G. Underwood (Ed.) Eye guidance in reading and scene perception, (p. 357-367). Oxford: Elsevier.

d'Ydewalle, G., \& Vanderbeeken, M. (1990). Perceptual and cognitive processing of editing rules in film. R. Groner, G. d'Ydewalle, \& R. Parnham (Eds.), From eye to mind: Information acquisition in perception, search, and reading. (pp. 129-139). Amsterdam: Elsevier (North Holland).

Dyer, A., MacSweeney, M., Szczerbinski, M., Green, L., \& Campbell, R. (2003) Predictors of Reading Delay in Deaf Adolescents: The Relative Contributions of Rapid Automatized Naming Speed and Phonological Awareness and Decoding. Journal of Deaf Studies and Deaf Education 8 (3), 215-229.

Easterbrooks, S. \& Stephenson, B. (2006). An examination of twenty literacy, science, and mathematics practices used to educate students who are deaf or hard of hearing. American Annals of the Deaf 151 (4), 385-397.

Hertzog, M. Stinson, M.S., \& Keiffer, R. (1989). Effects of caption modification and instructor intervention on comprehension of a technical film. Educational Technology Research and Development, 37, 59-68.

Holmqvist, K. et al. (2011). Eyetracking. A Comprehensive Guide to Methods and Measures. Oxford: Oxford University Press.

ITC Guidance on Standards for Subtitling, available at: http://www.ofcom.org.uk/static/archive/itc/itc_publica tions/codes_guidance/standards_for_subtitling/subtitli ng_1.asp.html

Jensema, C. (1998). Viewer reaction to different television captioning speeds. American Annals of the Deaf, 143(4), 318-324.

Jensema, C.J., Danturthi, R.S., \& Burch, R. (2000) Time spent viewing captions on television programs. American Annals of the Deaf, 145(5), 464-468. 
Kelly, L. (2003) The Importance of Processing Automaticity and Temporary Storage Capacity to the Differences in Comprehension Between Skilled and Less Skilled College-Age Deaf Readers. Journal of Deaf Studies and Deaf Education ,8(3), 230-249. DOI: 10.1093/deafed/eng013.

Koskinen, P.S., Wilson, T., \& Jensema, A. (1986) Closed-captioned television: A new technology for enhancing reading skills of learning disabled students. Spectrum, 4(2), 9-13.

R Development Core Team. (2011). R: A Language and Environment for Statistical Computing [Computer software manual]. Vienna, Austria.

Robson, G. (2004). The closed captioning handbook. Amsterdam: Elsevier.

Rodda, M., \& Grove, C. (1987). Language, cognition, and deafness. Hillsdale, NJ: Lawrence Erlbaum

Shroyer, E.H. \& Birch, J. (1980) Captions and reading rates of hearing-impaired students. American Annals of the Deaf 125(7), 16-22.

SMI Manual (2011) BeGaze Manual. Version 3.0.

Smith, T., \& Henderson J.M. (2008). Edit Blindness: The relationship between attention and global change blindness in dynamic scenes. Journal of Eye Movement Research 2(2): 6, 1-17.

Sokoli, S. (2011). Subtitling Norms in Greece and Spain. A comparative descriptive study on film subtitle omission and distribution. Unpublished doctoral thesis. Department of Translation and Interpreting, UAB.

Szarkowska, A., Krejtz, I., Kłyszejko, Z. \& Wieczorek, A. (2011). Verbatim, standard, or edited? Reading patterns of different captioning styles among deaf, hard of hearing, and hearing viewers. American Annals of the Deaf, 156 (4), 363-378.

Szarkowska A., Krejtz I., Łogińska M., Dutka Ł., Krejtz K. (2014). The influence of shot changes on reading subtitles - a preliminary study. Linguistics Applied. Audiovisual translation today: forms, trends, applications, 7.

Torres Monreal, S., \& Santana Hernández, R. (2005). Reading levels of Spanish deaf students. American Annals of the Deaf, 150(4), 379-387.
Trybus, R., \& Karchmer, M. (1977). School achievement scores of hearing impaired children: National data on achievement status and growth patterns. American Annals of the Deaf, 122, 62-69.

Ward, P., Wang, Y., Paul. P., \& Loeterman, M. (2007). Near-verbatim captioning versus edited captioning for students who are deaf or hard of hearing: A preliminary investigation of effects on comprehension. American Annals of the Deaf, 152(1), 20-28.

Wildblood, A. (2002). A Subtitle is Not a Translation: a day in the life of a subtitler. Language International Vol.14, No.2: 40-43. 